\title{
Load Frequency Control in Four Areas by using Fuzzy Logic Controller
}

\author{
Aldi Mucka \\ Faculty of Electrical Engineering \\ Polytechnic University of Tirana \\ Tirana, Albania
}

\author{
Gezim Karapici \\ Faculty of Engineering \\ Canadian Institute of Technology \\ Tirana, Albania
}

\begin{abstract}
For large scale electric power systems with interconnected areas Load Frequency Control (LFC) is important to keep the system frequency and the inter area tie power as near to the scheduled values as possible. The Load Frequency Control (LFC) problem is one of the most important subjects in the electric power system operation and control. In practical systems, the conventional PI type controllers are applied for Load Frequency Control. In order to overcome the drawbacks of the conventional PI controllers, numerous techniques have been proposed in literatures. In this paper, a Fuzzy type controller is considered for Load Frequency Control problem applied in four are power system. In this new Fuzzy technique, the upper and lower bounds of the Fuzzy membership functions are obtained by optimization method. A four-area electric power system with a wide range of parametric uncertainties is given, to illustrate proposed controller. To show effectiveness of the proposed controller, a classical PI type controller was designed in order to make comparison with the proposed Fuzzy controller by frequency response. The simulation and results are done by using SIMULINKIMATLAB package software.
\end{abstract}

Keywords-Four Areas System; Fuzzy Controller; Load Frequency Control; Electric Power System.

\section{INTRODUCTION}

The main objective of LFC in interconnected systems is to maintain the frequency at nominal values of the desired generation power output. There are various control techniques that have been applied to power and frequency control problems. The PI controller is among the simplest to implement but the set-up time is relatively large and causes a lot of oscillations in the frequency response. The best alternative to the PI controller is the widely used Fuzzy logic controller. In this paper, a Fuzzy type controller is considered for Load Frequency Control problem applied in four are power system. In this new Fuzzy technique, the upper and lower bounds of the Fuzzy membership functions are obtained by optimization method. A four-area electric power system with a wide range of parametric uncertainties is given, to illustrate proposed controller. To show effectiveness of the proposed controller, a classical PI type controller was designed in order to make comparison with the proposed Fuzzy controller by frequency response. The simulation and results are done by using SIMULINKIMATLAB package software. For each area is studied a system disturbance in the value of 0.02 p.u. or $40 \mathrm{MW}$. From simulation result are defined the frequency response, tie line active power difference, maximum deviation value of frequency and active power as well the graphic simulation the stand state error value. These values are compared for the respective models, zones and cases to see which type of controller gives the best performance in power frequency regulation of the power system.

\section{MATHEMATIC MODELS OF POWER SYSTEM ELEMENTS}

\section{A. Introduction}

The first step in the design of control systems and analysis is based in mathematical modeling of all power system elements. The two most commonly used methodologies are the transmitting function method and the variable of the state. Method variables of state can be applied to describe in the same time the linear and non-linear systems. To use the transmitting function and linear equations of state, the system must first be linearized. It is required to make approaches to the mathematical linearized equations that describe the system and so is obtained the transfer function model for the components to be checked.

\section{B. Generator model}

A small disturbance applied in the motion equation of a synchronous machine we get:

$$
\frac{2 H}{\omega_{s}} \frac{d^{2} \Delta \delta}{d t^{2}}=\Delta P_{m}-\Delta P_{e}
$$

Or the correlation with the speed change, if the speed is expressed in per unit, we get

$$
\frac{d \Delta \omega}{d t}=\frac{1}{2 H}\left(\Delta P_{m}-\Delta P_{e}\right)
$$

Applying Laplace transformation, we get the above correlation and it is represented by the following blockdiagram.

$$
\Delta \Omega(s)=\frac{1}{2 H s}\left(\Delta P_{m}(s)-\Delta P_{e}(s)\right)
$$

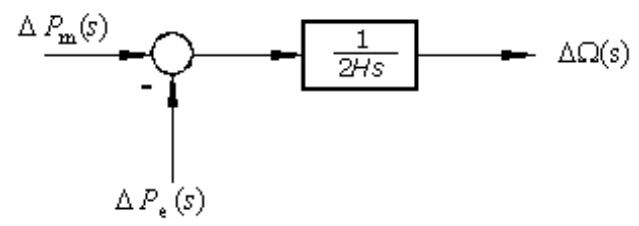

Fig. 1. Genarator Block model

\section{Loads Modeling}

The Power System load comprises from various electrical equipment. For such as active loads such as lighting and heat, electrical power does not depend on frequency. In the case of motor loads, such as pumps and fans, electrical power varies 
with frequency due to the change in rotor speed. This change is subject of speed-load ratio characteristics. This characteristic can be expressed as:

$$
\Delta P_{e}=\Delta P_{L}+D \Delta \omega
$$

The reduction coefficient expresses the percentage change of load for one percent of frequency change. For example, if the load changes $1 \%$ for a frequency change of $1 \%$, then $\mathrm{D}=1$. By including the load pattern in the generator block-diagram it is obtained the following block diagram.

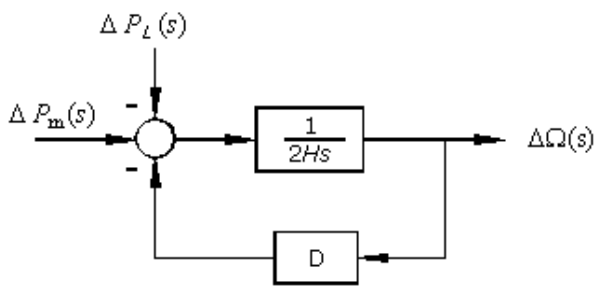

Fig. 2. Load and Generator block diagram

This type of load model is used in the power system modeling with four zones. In the absence of the Governor, the system load change reaction is determined by both of inertia and reduction coefficients. For constant speeds, the deflection is such that the change in load is completely offset by the load fluctuation due to frequency sensitivity.

\section{Primary mover (thermal and hydro turbine)}

The source of mechanical power, or otherwise known as the primary generator, can be a hydro or a steam turbine, which gets the power from the burning energy from coal, oil, gas, and nuclear resources. The turbine model associates the changes in mechanical power output to the changes in the steam valves position. The characteristics of different turbines may widely vary in their family range. The simplest model of the primary generator for non-reheated steam turbines can be approximated with a time constant which leads us to the following transmission function:

$$
G_{T}(s)=\frac{\Delta P_{m}(s)}{\Delta P_{V}(s)}=\frac{1}{1+\tau_{T} s}
$$

The block-diagram of a general turbine as is shown in Figure 3. The time coefficient is within the limits from 0.2 to 2.0 seconds.

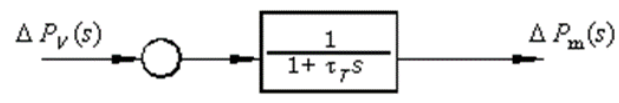

Fig. 3. Block diagramof stean turbine non-reheated Another type of steam turbine is called reheated steam turbine. The dynamic response of a steam turbine to the term of the output power change can be expressed as the change in steam valve opening. The relevant block-diagram of reheated steam turbine is shown in Figure 4. For simplicity study it is assumed that the turbine can be modeled with a single equivalent time coefficient is in the range of 0.2 to 2.5 seconds.

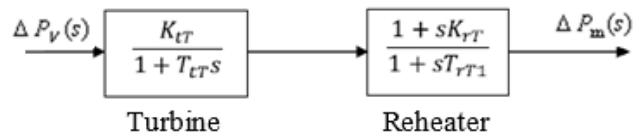

Fig. 4. Block diagram of steam turbine with reheater The modeling of the hydro turbine can be achieved from the turbine flow equations, the mechanical moment and the correlation of these equations to each other. The turbine flow equation states and the mechanical moment of the turbine is expressed as is show in Equation 6 and 7.

$$
\begin{aligned}
& q_{t}=g+0.5 h \\
& M=g+1.5 h
\end{aligned}
$$

The gate "g" position and hash " $h$ " are related to an impedance function

$$
\frac{h}{q_{t}}=T_{w} s
$$

The above three equations with numerical processing give the formula of the hydro turbine transmission function as is show in Equation 9.

$$
\frac{M}{g}=\frac{1-T_{w} s}{1+0.5 T_{w} s}
$$

\section{E. Governor Model}

When the machine (generator) load is increased instantaneously, the active power exceeds the amount of mechanical power at the inlet of the turbine. This power deficit is covered by the kinetic energy stored by the rotating masses. The decrease in kinetic energy causes the turbine speed to decrease and consequently will cause the frequency to drop. The difference in speed is detected by the speed control, which tends to adjust the valves at the inlet of the turbine in order to change the mechanical energy at the outlet of the turbine and keep the speed in another steady mode. Modern controllers use the electronic way to understand speed changes and often use the combination of electronic, mechanical and hydraulic tools to make the necessary changes to the valve position. This type of controller is called a onetime controller (at constant speed), regulates valve entry at the point that drives the frequency back to its nominal value. If the output of the speed-sensitive mechanism is directly linked to the valve, the frequency is not likely to be brought to nominal value. The governor block diagram shown in Figure 5 can be reduced as in the form shown in Figure 6. This type of speed controller is known as proportional controller with amplifier $1 / \mathrm{R}$.

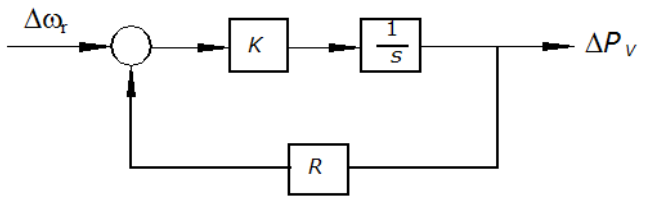

Fig. 5. Block diagram of governor

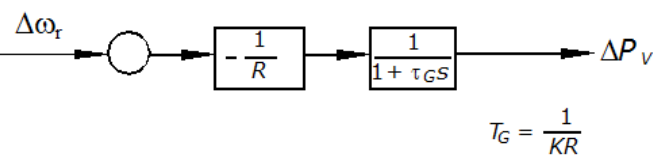

Fig. 6. Block diagram of reduced governor 
The slope of the curve $\mathrm{R}$ represents the drop of static characteristic. Controllers typically have a drop of (5-6) \% from zero to nominal load. Drop represents the relationship between the speed change $(\Delta \omega)$ or frequency change $(\Delta f)$ and the change the power generated or the change of the position of the valve/gate. The transfer function of governor as is $\mathrm{m}$ shown in Equation 10.

$$
G_{g}(s)=\frac{1}{T_{G} s+1}
$$

\section{F. Tie Line model}

In figure 7 are show two power systems connected with one tie line. Both areas are represented by one equivalent generating unit interrelated with each other with a tie line with no losses, with the reactance $\mathrm{X}_{\text {tie }}$ of line.

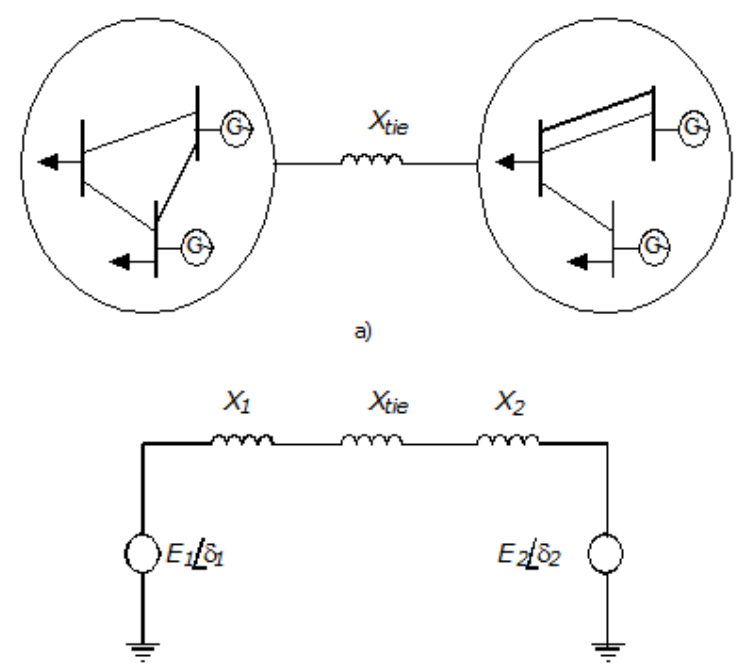

b)

Fig. 7. a) Two area of interconnected power system. b) Equivalent circuit

The areas are represented by a voltage source and an equivalent reactance. The active power transmitted over the tie line is:

$$
P_{12}=\frac{\left|E_{1}\right|\left|E_{2}\right|}{X_{12}} \sin \delta_{12}
$$

Equation (11) may be linearized for a small deviation from the power flow nominal $\Delta \mathrm{P}_{12}$.

$$
\Delta P_{12}=\left.\frac{d P_{12}}{d \delta_{12}}\right|_{\delta_{120}} \Delta \delta_{12}=P_{s} \Delta \delta_{12}
$$

$\mathrm{P}_{\mathrm{s}}$ presents to the slope of the power angle curve for a preliminary angle $\delta_{12}=\delta_{1}-\delta_{2}$. This can be defined as the coefficient of synchronous power. Given this we get:

$$
P_{s}=\left.\frac{d P_{12}}{d \delta_{12}}\right|_{\delta_{120}}=\frac{\left|E_{1}\right|\left|E_{2}\right|}{X_{12}} \cos \Delta \delta_{120}
$$

And the deviation of power in the interconnection line will take the form:

$$
\Delta P_{12}=P_{s}\left(\Delta \delta_{1}-\Delta \delta_{2}\right)
$$

\section{FUZZY LOGIC AND FUZZY CONTROLLER}

\section{G. Fuzzy Logic}

The theory of Fuzzy logic can be seen as a generalization of classical logic theory, so the basic knowledge of classical (Boolean) logic is first given as a reference for the development of fuzzy logic theory. Fuzzy logic has two different meanings. In a narrow sense it is a logical system. In another sense it is synonymous with Fuzzy set theory, which refers to sets of objects that have indefinite boundaries, and being part of these sets is defined in percentage quantitative levels. So, an element may be part of a community, partially avoided evaluation, is complete or not at all. This is expressed by the fuzzy theory. And in the first sense, Fuzzy logic differs in concept and substance with traditional logic systems. Fuzzy Logic system is characterized by the following elements:

- Input membership function

- Fuzzy rules

- Output membership function

After defining such a system, the question is how we will use this system, how we will put it into operation. What ways and methods will be used to analyze the totality of information in the input of this system in order to have a single logical outcome on which to base decision making. Using these elements and their properties processes and actions in a Fuzzy system will go through several stages listed as follows:

- Enabling Entries.

- Fuzzy judgment.

- Composite Fuzzy output.

- Defuzzification.

\section{H. Fuzzy Controller}

In this paper the Fuzzy controller proposed is with two inputs and one output membership functions. On input is the area control error signal and second is the speed change of area control error signal. The output of Fuzzy controller is the control function applied for control the system. The following Figure 8 show the Fuzzy controller used in linearizing the power system with four areas.

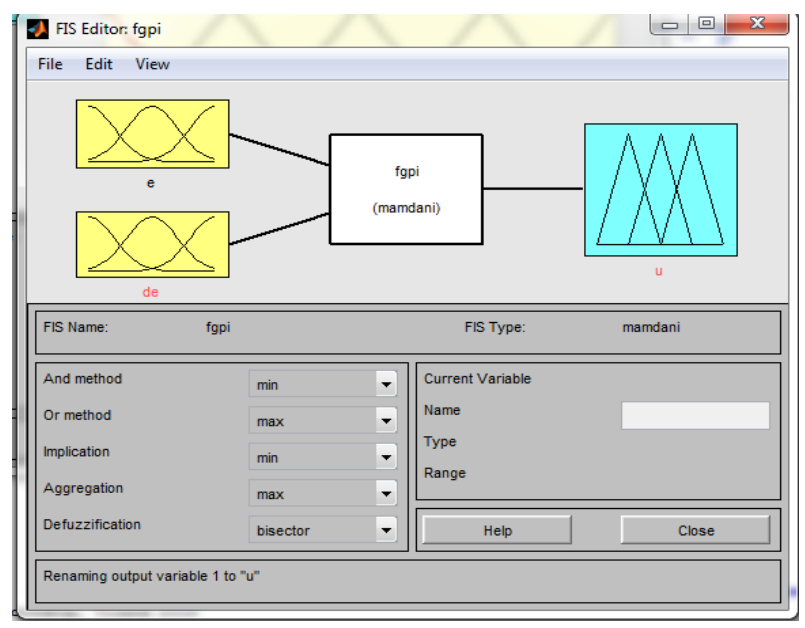

Fig.8. Fuzzy controller model used in power system 
The following are the features of the Fuzzy logic of the proposed Fuzzy controller.

[System]

Name='fgpi'

Type='mamdani'

Version $=2.0$

NumInputs $=2$

NumOutputs $=1$

NumRules $=25$

AndMethod='min'

OrMethod='max'

ImpMethod='min'

AggMethod='max'

DefuzzMethod='bisector'

[Input1]

Name $={ }^{\prime} E^{\prime}$

Range $=\left[\begin{array}{ll}-0.001 & 0.001\end{array}\right]$

NumMFs $=5$

MF1='NB':'trimf',[-0.0015 -0.001 -0.0005002]

MF2='NS':'trimf', [-0.001 -0.00050020$]$

MF3='ZZ':'trimf',[-0.0005002 00.0004998$]$

MF4='PS':'trimf',[0 0.00049980 .001$]$

MF5='PB':'trimf',[0.0004998 0.0010 .0015$]$

[Input2]

Name $={ }^{\prime} \mathrm{dE}$ '

Range $=\left[\begin{array}{ll}-0.01 & 0.02\end{array}\right]$

NumMFs $=5$

MF1='NB':'trimf',[-0.0175 -0.01 -0.0025]

MF2='NS':'trimf',[-0.01 -0.0025 0.005]

MF3='ZZ':'trimf', [-0.0025 0.0050 .0125$]$

MF4='PS':'trimf',[0.005 0.0125 0.02]

MF5='PB':'trimf',[0.0125 0.02 0.0275]

[Output1]

Name $=$ ' $u$ '

Range $=\left[\begin{array}{ll}0 & 2\end{array}\right]$

NumMFs $=5$

MF1='S':'trimf',[- $\left.\begin{array}{lll}-0.5 & 0 & 0.5\end{array}\right]$

MF2='M':'trimf',[0 0.5 1]

MF3='B':'trimf', [l $\left.\begin{array}{lll}0.5 & 1 & 1.5\end{array}\right]$

MF4='VB':'trimf', [1 11.52$]$

MF5='VVB':'trimf',,[ll $\left.\begin{array}{lll}1.5 & 2 & 2.5\end{array}\right]$

[Rules]

1 1, 1 (1):1; $12,1(1): 1 ; 13,2(1): 1 ; 14,2$ (1): 1;

15,3 (1): 1; $21,1(1): 1 ; 22,2$ (1): $1 ; 23,2$ (1): 1 ;

24,3 (1): 1; 2 5, 4 (1): 1; 3 1, 2 (1): 1;3 2, 2 (1): 1;

3 3, 3 (1): 1; 34,4 (1): 1; 3 5, 4 (1): 1; 4 1, 2 (1): 1 ;

4 2, 3 (1): 1 ; 43,4 (1): 1; 4 4, 4 (1): 1; 4 5, 5 (1): 1 ;

5 1, 3 (1): 1; 52,4 (1): 1; 53,4 (1): 1; 54,5 (1): 1 ;

$55,5(1): 1$

\section{PLANT MODEL}

Electric Power Systems have variable and complicated features and include various parts of control, many of which are nonlinear. The systems are interconnected with tie line and need control frequency and power. Multi-area interconnected power systems can be described using circles. A simple four-area interconnected system is the connection of the Albanian power system to neighboring electricity systems such as Greece, Montenegro and Kosovo used in this study. In Figure 9 and Figure 10 is show the interconnection of these power systems and Matlab/Simulink model for this study.

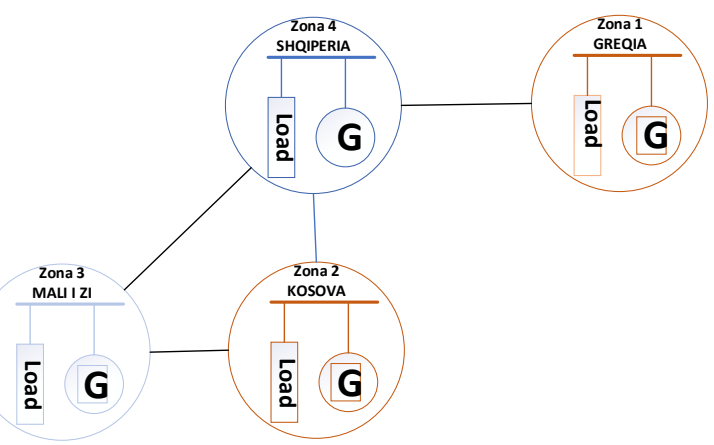

Fig. 9. Four-area electric power system with interconnections

In Load Frequency Control model, it's assumed there are three types of turbines, Area 4 (Albania) and Area 1 (Montenegro) with hydraulic turbine unit Area 2 (Kosovo) with non-reheating turbine unit, Area 3 (Greece) with reheating turbine units and, which are modeled by the respective transmission functions for each of them.

The nomenclatures of the above equations are defined as follows:

$\Delta \mathrm{P}_{\mathrm{G}}=$ Generated power derivation, pu MW.

$\Delta \mathrm{P}_{\mathrm{D}}=$ Change in power demand, pu MW.

$\Delta \mathrm{P}_{\mathrm{C}}=$ Change in speed changer position $(\mathrm{u}), \mathrm{pu} \mathrm{MW}$.

$\Delta \mathrm{f}=$ Derivative in frequency, $\mathrm{Hz}$.

$\mathrm{K}_{\mathrm{P}}=$ Static gain of power system inertia dynamic block, $\mathrm{Hz} / \mathrm{pu} \mathrm{MW}$.

$\mathrm{T}_{\mathrm{P}}=$ Time constant of power system inertia dynamic block, $\mathrm{s}$. $\mathrm{T}_{\mathrm{G}}=$ Governor Time constant, $\mathrm{s}$.

$\mathrm{T}_{\mathrm{T}}=$ Turbine (non-reheat type) time constant, $\mathrm{s}$.

$\mathrm{R}=$ Speed regulation parameter, $\mathrm{Hz} / \mathrm{pu} \mathrm{MW}$.

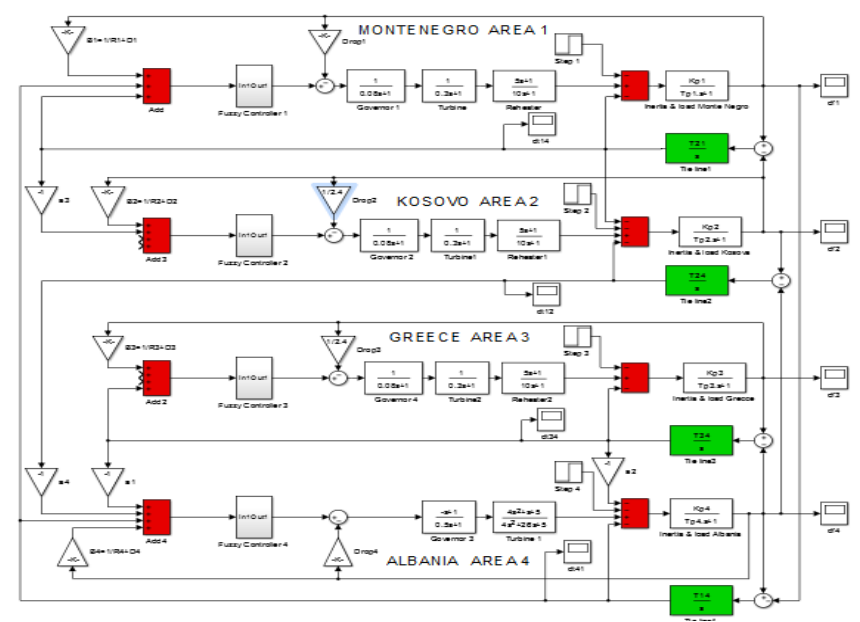

Fig. 10. Block Diagram of four areas power system with Fuzzy controller in Simulink work space 


\section{SIUMALTION REZULTS}

The following is a table of the nominal power system parameters needed to build and implement the power system on the Matlab/ Simulink software platform.

\begin{tabular}{|c|c|c|c|}
\hline \multicolumn{2}{|c|}{ TABLE I. } & \multicolumn{2}{|c|}{ YSTEM PARAMETES DATA } \\
\hline $\begin{array}{c}\text { Area 1 } \\
\text { Montenegro }\end{array}$ & $\begin{array}{l}\text { Area } 2 \\
\text { Kosovo }\end{array}$ & $\begin{array}{l}\text { Area } 3 \\
\text { Greece }\end{array}$ & $\begin{array}{c}\text { Area } 4 \\
\text { Albania }\end{array}$ \\
\hline $\begin{array}{c}\mathrm{M}_{1}=10.0 \\
\left(\mathrm{pu}^{*} \mathrm{~s}\right)\end{array}$ & $\begin{array}{c}\mathrm{M}_{2}=9.0 \\
\left(\mathrm{pu}^{*} \mathrm{~s}\right)\end{array}$ & $\begin{array}{c}\mathrm{M}_{2}=11.0 \\
\left(\mathrm{pu}^{*} \mathrm{~s}\right)\end{array}$ & $\begin{array}{c}\mathrm{M}_{4}=6.0 \\
\left(\mathrm{pu}^{*} \mathrm{~s}\right)\end{array}$ \\
\hline $\begin{array}{c}\mathrm{D}_{1}=0.008 \\
\left(\mathrm{pu}^{*} \mathrm{~Hz}\right)\end{array}$ & $\begin{array}{c}\mathrm{D}_{2}=0.007 \\
\left(\mathrm{pu}^{*} \mathrm{~Hz}\right)\end{array}$ & $\begin{array}{c}\mathrm{D}_{3}=0.094 \\
\left(\mathrm{pu}^{*} \mathrm{~Hz}\right)\end{array}$ & $\begin{array}{c}\mathrm{D}_{4}=0.0085 \\
\left(\mathrm{pu}^{*} \mathrm{~Hz}\right)\end{array}$ \\
\hline $\mathrm{Tch}_{1}=0.3(\mathrm{~s})$ & $\mathrm{Tch}_{2}=0.3(\mathrm{~s})$ & $\mathrm{Tch}_{3}=0.4(\mathrm{~s})$ & $\begin{array}{c}\mathrm{Kd}=4, \mathrm{Ki}=5, \\
\mathrm{Kp}=1, \mathrm{Tw} 4=1 \mathrm{~s}\end{array}$ \\
\hline $\operatorname{Tr}_{1}=0.1(\mathrm{~s})$ & $\operatorname{Tr}_{2}=0.1(\mathrm{~s})$ & $\mathrm{Tr}_{3}=0.15(\mathrm{~s})$ & \\
\hline $\mathrm{Tt}_{1}=0.1(\mathrm{~s})$ & $\mathrm{Tt}_{2}=0.5(\mathrm{~s})$ & $\mathrm{Tt} 3=0.15(\mathrm{~s})$ & $\mathrm{Tt}_{4}=0.5(\mathrm{~s})$ \\
\hline $\begin{array}{c}\mathrm{R}_{1}=2.4 \\
(\mathrm{hz} / \mathrm{pu})\end{array}$ & $\begin{array}{c}\mathrm{R}_{2}=2.1 \\
(\mathrm{hz} / \mathrm{pu})\end{array}$ & $\begin{array}{c}\mathrm{R}_{3}=2.9 \\
(\mathrm{hz} / \mathrm{pu})\end{array}$ & $\begin{array}{c}\mathrm{R}_{4}=3.86 \\
(\mathrm{hz} / \mathrm{pu})\end{array}$ \\
\hline $\mathrm{B}_{1}=0.401$ & $\mathrm{~B}_{2}=0.300$ & $\mathrm{~B}_{3}=0.480$ & $\mathrm{~B}_{4}=0.274$ \\
\hline $\mathrm{T}_{14}=0.075$ & $\mathrm{~T}_{24}=0.052$ & $\mathrm{~T}_{34}=0.098$ & $\mathrm{~T}_{41}=0.075$ \\
\hline
\end{tabular}

The scheme of connecting the plant to Fuzzy controller is simulated also with PI controller in order to make comparison of results. A positive disturbance (load change) is presented in the system in zone 1 and 2 with a value 0.02 p.u or $40 \mathrm{MW}$ and a disturbance in zone 3 and 4 of the same value. The total power generation per each area is 2000 MW and the maximum interconnection line capacity is $200 \mathrm{MW}$.

Figure 11 and 12 shows frequency response in area 1 and 2 for PI and Fuzzy controllers. The both controllers reduce the stand state error to 0 and the set value of frequency is $50 \mathrm{~Hz}$. While in the set time the Fuzzy controller is very fast its set time is 11 seconds compare with PI controller respectively 50 seconds. The over shoot values of the frequency deviations for the case of the scheme with Fuzzy and PI controllers are -0.02 p.u. and -0.1 p.u.

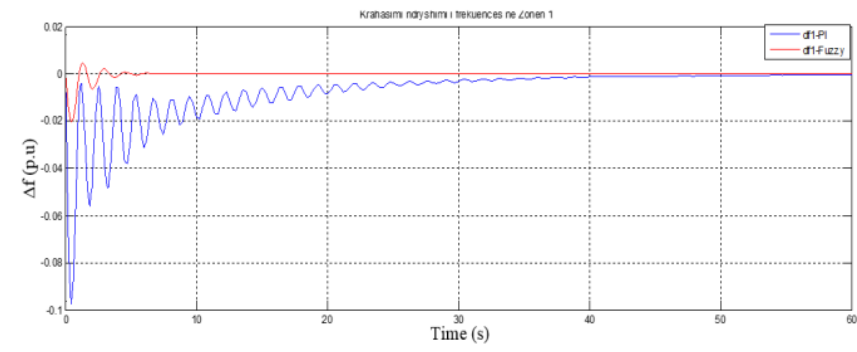

Fig. 11. Frequency response in area 1 by using PI and Fuzzy ontrollers

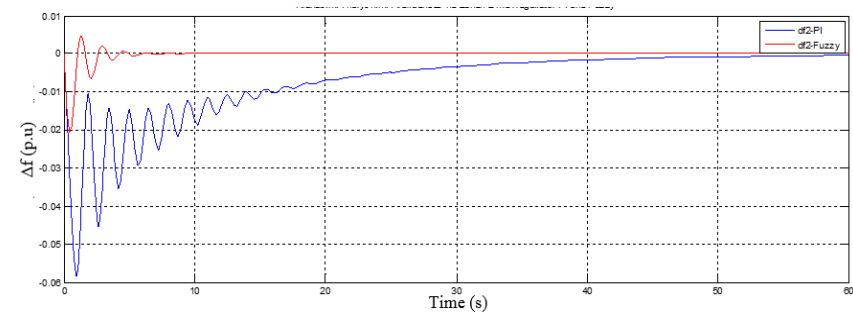

Fig. 12. Frequency response in area 2 by using PI and Fuzzy ontrollers

In figures 13 is show the power deviation for tie line between areas. For example, the maximum power exchange between area 1 and 2 for the case with PI and Fuzzy controllers is -
0.028 p.u. and -0.011 p.u. By compare the setting time for the both controllers are observed that Fuzzy controller is very fast.

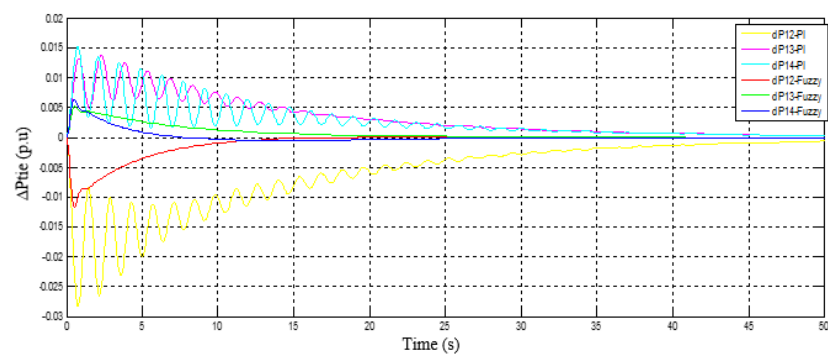

Fig. 13. Power exchange response between Areas for both controllers

Figures 14 show the power area control error for all areas. From the results is show very clear that all performance indicator of transient response they are obviously very good when it is used Fuzzy controller.

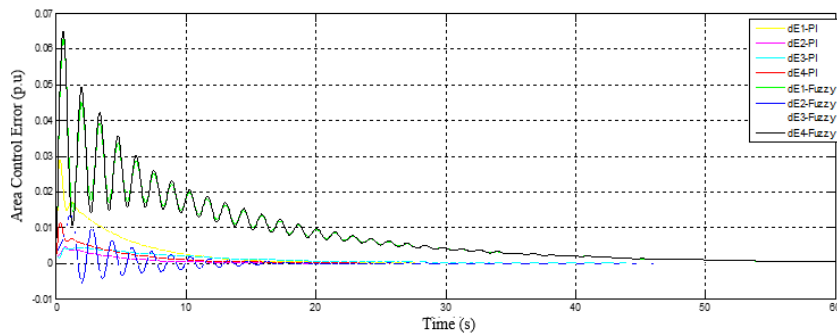

Fig. 14. Area Control Error response for both controller

The above results obtained from the simulations show that the proposed use of Fuzzy controllers in the interconnected power system enables a better dynamic performance in terms of system power-frequency control by reducing static error and frequency deviation oscillations and of power in tie lines in any area with the combination of thermo and hydro in a relatively short time. The setting time and overshoot of response of the frequency and power exchange in the tie line are shown in Tables from 2 to 5 for the power system with four area model selected by using PI and Fuzzy controllers.

TABLE II. COMPARISON OF SETTING TIME OF FREQUENCY

\begin{tabular}{|c|c|c|c|c|}
\hline Controller & $\begin{array}{c}\text { Area 1 } \\
\text { Montenegro } \\
(\boldsymbol{s})\end{array}$ & $\begin{array}{c}\text { Area 2 } \\
\text { Kosovo } \\
(\boldsymbol{s})\end{array}$ & $\begin{array}{c}\text { Area 3 } \\
\text { Greece } \\
(\boldsymbol{s})\end{array}$ & $\begin{array}{c}\text { Area 4 } \\
\text { Albania } \\
(\boldsymbol{s})\end{array}$ \\
\hline PI & 50 & 45 & 57 & 45 \\
\hline Fuzzy & 11 & 10.2 & 10.3 & 12 \\
\hline
\end{tabular}

TABLE III. COMPARISON OF SETTING TIME OF POWER EXCHANGE RESPONSE

\begin{tabular}{|c|c|c|c|c|}
\hline Controller & $\begin{array}{c}\text { Tie Line 1-2 } \\
(\boldsymbol{s})\end{array}$ & $\begin{array}{c}\text { Tie Line 2-4 } \\
(\boldsymbol{s})\end{array}$ & $\begin{array}{c}\text { Tie Line 3-4 } \\
(\boldsymbol{s})\end{array}$ & $\begin{array}{c}\text { Tie Line 4-1 } \\
(\boldsymbol{s})\end{array}$ \\
\hline PI & 55 & 47 & 49 & 44.5 \\
\hline Fuzzy & 25 & 21.2 & 23 & 19.2 \\
\hline
\end{tabular}


TABLE IV. COMPARISON OF OVERSHOOT FREQUENCY RESPONSE

\begin{tabular}{|c|c|c|c|c|}
\hline Controller & $\begin{array}{c}\text { Area 1 } \\
\text { Montenegro } \\
(\text { p.u })\end{array}$ & $\begin{array}{c}\text { Area 2 } \\
\text { Kosovo } \\
(\text { p.u })\end{array}$ & $\begin{array}{c}\text { Area 3 } \\
\text { Greece } \\
(\text { p.u })\end{array}$ & $\begin{array}{c}\text { Area 4 } \\
\text { Albania } \\
(\text { p.u })\end{array}$ \\
\hline PI & -0.1 & -0.06 & -0.08 & -0.09 \\
\hline Fuzzy & -0.02 & -0.021 & -0.01 & -0.04 \\
\hline
\end{tabular}

TABLE V. COMPARISON OF OVERSHOOT POWER EXCHANGE

\begin{tabular}{|c|c|c|c|c|}
\hline Controller & $\begin{array}{c}\text { Tie Line 1-2 } \\
(\boldsymbol{p} . u)\end{array}$ & $\begin{array}{c}\text { Tie Line 2-4 } \\
(\boldsymbol{p} . \boldsymbol{u})\end{array}$ & $\begin{array}{c}\text { Tie Line 3-4 } \\
(\boldsymbol{p} . \boldsymbol{u})\end{array}$ & $\begin{array}{c}\text { Tie Line 4-1 } \\
(\boldsymbol{p} . \boldsymbol{u})\end{array}$ \\
\hline PI & -0.03 & 0.013 & 0.014 & 0.015 \\
\hline Fuzzy & -0.013 & 0.007 & 0.008 & 0.006 \\
\hline
\end{tabular}

\section{CONCLUSION}

In this paper has been analyses the performance of two different controller in load frequency control of an interconnected powers system. The proposed Fuzzy controller was applied to a typical four areas with different generation turbines. The simulation results demonstrated that the proposed controller is capable to guarantee the robust stability and robust performance. This in the terms of precise reference frequency tracking and disturbance attenuation, under a wide range of load changes. Also, the simulation results showed that the Fuzzy controller has better performance than the conventional PI type controller at all operating conditions.

\section{REFERENCES}

[1] C. Concordia and L.K. Kirchmayer, 'Tie line power and Frequency control of electric power systems,' Amer. Inst. Elect. Eng. Trans., Pt. II, Vol. 72, pp. 562-572, Jun. 1953.

[2] IEEE PES Working Group, 'Hydraulic turbine and turbine control models for system dynamic Studies,' IEEE Trans. Power Syst., vol. PWRS-7, no. 1, pp. 167-174, Feb. 1992.

[3] V. Konomi, "Load Frequiency Control on Interconection Power Sysems", Tirana 2008.

[4] C.S. Chang and W. Fu "Area load frequency control using fuzzy gain scheduling of PI controllers," Electrical Power and Energy Systems, vol. 42, no. 9, pp. 125-133, 1997.

[5] L. A Zadeh, R. A Live,'Fuzzy Logic Theory and Applications" Word Scientific Publishing Co.Pte.Ltd, 5 Toh Tuck Lik, Singapore 596224.

[6] Y.H. Song and A.T. Johns, "Applications of fuzzy logic in power systems: part 1 general introduction to fuzzy logic," Power Engineering Journal, pp. 219-222, 1997.

[7] H.A. Yousel, K.A.L. Kharusi, M.H. Albadi, N. Hosseinzadeh, Load frequency control of a multi-area power system: an adaptive fuzzy logic approach, IEEE Trans. Power Syst. 29 (4) (2014) 1822-1830. 